\title{
Effect of relaxation therapy on depression, anxiety, stress and quality of life among diabetic patients
}

\author{
Sabah M. Ebrahem*1, Samah E. Masry² \\ ${ }^{1}$ Psychiatric Nursing, Faculty of Nursing, Menoufia University, Egypt \\ ${ }^{2}$ Medical Surgical Nursing, Faculty of Nursing, Menoufia University, Egypt
}

Received: September 11, 2016

Accepted: January 11, 2017

Online Published: January 19, 2017

DOI: $10.5430 /$ cns.v5n $1 \mathrm{p} 35$

URL: http://dx.doi.org/10.5430/cns.v5n1p35

\begin{abstract}
Objective: The goal of this study was to evaluate the effect of relaxation therapy on depression, anxiety, stress, quality of life, and blood glucose levels among patients diagnosed with type II diabetes mellitus (T2DM).

Methods: A quasi-experimental research design was used. Sample: Convenience sample of 70 patients was recruited and assigned to one of two groups, an intervention group (Group A) and a control group (Group B). A table of random numbers was generated and used to make group assignments. Setting: The study was conducted at Medical Outpatient Clinics in Menoufia University Hospital, Menoufia governorate, Egypt. Instruments: Data collection included a structured interview questionnaire that included socio-demographic characteristics and clinical data, the Depression, Anxiety and Stress Scale (DASS), and the World Health Organization Quality of Life (WHOQOL-BRIEF).

Results: The findings indicate that anxiety level, stress, depression, and quality of life were improved in the intervention group with a statistically significant degree compared to the control group.

Conclusions: Relaxation therapy improved depression, anxiety, stress, quality of life, and blood glucose levels among patients diagnosed with T2DM.

Recommendation: Relaxation therapy, patient education programs and treatment protocols should be integrated into the medical outpatient clinic to assist patients diagnosed with T2DM to cope with their stress, anxiety, depression, and enhance blood glucose control.
\end{abstract}

Key Words: Anxiety, Stress, Depression, Quality of life, Relaxation therapy, Diabetes

\section{INTRODUCTION}

The number of people with diabetes has risen from 108 million in 1980 to 422 million in 2014, the global prevalence of diabetes among adults over 18 years of age has risen from $4.7 \%$ in 1980 to $8.5 \%$ in 2014. Diabetes prevalence has been rising more rapidly in middle and low-income countries. ${ }^{[1]}$ Globally, diabetes is still a rising in epidemic proportions, exhibiting the most striking increase in third world countries with emerging economies. This phenomenon is particularly evident in the Middle East and North Africa (MENA) region, Egypt and Saudi Arabia are on the separate ends of the spectrum with regard to diabetes prevalence in the MENA region with Egypt having the lowest rate at $7.2 \%$ and Saudi Arabia the highest at $21.8 \%{ }^{[2]}$

The WHO (EMRO region) has identified diabetes as one of the health priorities and challenges in Egypt with a prevaEgypt.

*Correspondence: Sabah M. Ebrahem; Email: dr.sabah20@ gmail.com; Address: Psychiatric Nursing, Faculty of Nursing, Menoufia University, 
lence around $9 \%$ in the entire country and high prevalence of the pre-diabetic state of $11 \%$ in Cairo, $7 \%$ in Menoufia and $18 \%$ in Sohag. ${ }^{[3]}$ Regardless socioeconomic status, urban populations within Egypt have higher diabetes prevalence rates compared to rural populations. The increased the prevalence of diabetes in urban areas could be associated with decreased physical activity and increased prevalence of obesity. ${ }^{[4]}$

However, it is well documented that depression, anxiety, and stress symptoms are highly prevalent among diabetic patients than those without diabetes; the prevalence of severe anxiety was $35.3 \%$ vs. $16.3 \%$, severe depression was $13.6 \%$ vs. $5.9 \%$, and severe stress was $46.6 \%$ vs. $21.7 \% .^{[5]}$ Anxiety disorders represent an exaggerated emotional response to the fears. People with diabetes are at higher risk for these disorders because they often live with sources and levels of fear greater than those most people experience such as fear of hypoglycemia, complications, and the effects of diabetes daily life. ${ }^{[6]}$

Stress is "a state of physical and psychological tension". [7] The relationship between stress and glycemic control is complex. Stress can affect blood glucose level in different ways, the first are the physiological responses: increased heart rate; peripheral vasoconstriction; elevated skeletal muscle activity; increased hormone release (pituitary, corticosteroids, catecholamines); and, inhibited insulin production, responses that contribute to increased blood glucose levels. ${ }^{[8]}$ The second, psychological responses; can also affect self-management abilities and can negatively influence the individual's health care practices which are essential to successful self-management. ${ }^{[9]}$

Diabetes not only negatively affects physical functioning (e.g. decreased energy) but psychological status (e.g. depression and stress) and social relationships, which in turn affects the quality of life. ${ }^{[10]}$ Health-related quality of life is the value assigned to duration of life as modified by the impairments, functional status, perceptions and social opportunities influenced by disease, injury, treatment or policy. ${ }^{[11]}$ When talking about the quality of life in diabetic patients should consider the personal side of diabetes, the perceived burden of living with the illness, different clinical features of diabetic patients and type of complications can be critical components of the global individual perception of quality of life. ${ }^{[12]}$

Stress can be a short or long term and the behavioral response of the individual is influenced by social supports, coping ability and other psychosocial factors. Experiences of stress aggravate unhealthy habits such as smoking. In addition, an increase in blood glucose level increases the complica- tions. ${ }^{[13]}$ The management of diabetics requires a lifestyle modification and intensive self-management strategies which include; strict diet, exercise, and blood glucose monitoring and medication management which add stress to the patient. Comprehensive education, diabetes self-management training, follow-up and ongoing social support is required for diabetic patients and their families. ${ }^{[14,15]}$

For some people with diabetes, controlling stress with relaxation therapy seems to help, though it is more likely to help people with type II diabetes than people with type I diabetes. This difference makes sense. Stress blocks the body from releasing insulin in people with type II diabetes, so cutting stress may be more helpful for these people. People with type I diabetes don't make insulin, so stress reduction doesn't seem to have this effect. Some people with type II diabetes may also be more sensitive to some of the stress hormones. Relaxing can help by blunting this sensitivity. ${ }^{[16]}$

Dunning ${ }^{[17]}$ reported that complementary and alternative therapies can reduce stress, anxiety, depressive symptoms among diabetics, and help them develop sustainable strategies to prevent stress. Regular progressive muscle relaxation exercise can control metabolism process, decrease blood sugar level, decrease catecholamines, and decreasing activity of the autonomic nervous system and induce a physical and mental relaxation. ${ }^{[18]}$ Relaxation can improve the function of the brain, blood circulation, and increase endorphins secretion, also inhibits the adrenal gland and can improve anxiety and stress level which can help in controlling blood pressure and blood glucose level. ${ }^{[19]}$

\subsection{Significance of the study}

The global epidemic of type II diabetes is a major public health problem, the world prevalence in 2010 among adults estimated to be more than six percent. Over the next twenty years, the number of adults living with diabetes will be increased to twenty percent in the developed world. ${ }^{[20]}$ As the prevalence of diabetes rises, it is important to improve the treatment outcomes and the prevention of complications among those affected.

Psychological distress and symptoms of depression tend to be very common in patients with diabetes and are more closely related to diabetes control, treatment nonadherence and risk of complications and mortality. ${ }^{[21]}$ Moreover, Mitsonis et al. ${ }^{[22]}$ reported that $14 \%$ of patients with diabetes have generalized anxiety disorder. Tuncay et al. ${ }^{[23]}$ reported that maladaptive coping could increase the risk for anxiety in patients with diabetes and patients who use both task-based coping and emotion-based coping, have better emotion regulation and diabetes control. Conversely, emotion-based coping, 
such as anxious and angry styles, is associated with poor glycemic control. Changing the reactions to stress through relaxation therapy, stopping techniques, reflection, and meditation can prevent anxiety and rage. Relaxation can prevent stress, the negative consequences of the impulsive behaviors, and improve a quality of life of diabetic patients. ${ }^{[8]}$

As the prevalence of diabetes raise, there is a need to reduce its complications through adherence to pharmacological treatment, diabetes control, and application of nursing intervention programs that include changing eating habits, reduce physiological effects of stress, and improve the quality of life of the patients with diabetes. From the review of the literature, stress can aggravate the symptoms of diabetes and diabetes itself can be a source of stress among diabetic patients. So too does the importance of improving the treatment outcomes and the prevention of complications among those affected.

\subsection{Aim of the study}

The aim of this study is to evaluate the effect of relaxation therapy on depression, anxiety, stress, quality of life, and blood glucose levels among patients diagnosed with type II diabetes mellitus (T2DM).

\subsection{Research hypothesis}

(1) Relaxation therapy has a significant effect on decreasing blood glucose level.

(2) Relaxation therapy has a significant effect on improving depression, anxiety, stress and quality of life.

\section{SubJECTS AND METHOdS}

A quasi-experimental research design was used in the current study and was implemented at Medical Outpatient Clinics in Menoufia University Hospital, Menoufia University, Egypt. A convenience sample of 70 patients diagnosed with type II diabetes of both sexes and aged 30 years old or more was recruited. They were divided equally into two groups: (A) intervention group, and (B) control group using the table of random numbers. Accordingly, numbers 0-4 and 5-9 were assigned to (A) and (B) respectively. Patients of group (A) attended 8 weekly sessions of relaxation therapy while other patients of group (B) follow routine care. The study carried out throughout the period from September 2015 to January 2016. Inclusion criteria were adult patients who diagnosed with type II diabetes and free from cardiac disease, and the exclusion criteria were the patients who receive any treatment for depression or anxiety, any prior training about relaxation therapy, pregnant and lactated women. Sample size was determined for the study using Epi Info (2000) pro-

Published by Sciedu Press gram based on the total number of population in Menoufia governorate was $3,849,850,7 \%$ prevalence rate of diabetes in Menoufia, at $90 \%$ confidence interval to obtain suitable sample size according to available patient attending outpatient clinic during study using $95 \%$ give us larger sample than available to us.

\subsection{Instruments of the study}

Three Instruments were used for data collection for this study based on extensive review of the literature. These instruments were:

Instrument (1): Structured interview questionnaire:

The instrument was developed and used by the researchers based on the review of the relevant literature. It included data related to sociodemographic characteristics and clinical data: such as age, sex, educational level, occupation, marital status, history of associated diseases, family history and blood glucose level.

Instrument (2): Depression, Anxiety and Stress Scale (DASS):

DASS was developed in 1995 by Lovibond and Lovibond. ${ }^{\text {[24] }}$ The Arabic version was developed and tested for content validity and reliability by Taouk et al. ${ }^{[25]}$ The scale consists of 42 items and covers three subscales. DASS measures the negative emotional states of depression, anxiety, and stress. Each of the three subscales contains 14 items. The depression items include: dysphoria, hopelessness, devaluation of life, self-deprecation, and lack of interest/involvement, anhedonia, and inertia. The anxiety items include: autonomic arousal, skeletal muscle effects, situational anxiety, and subjective experience of anxious affect. The stress items include: difficulty relaxing, nervous arousal, and being easily upset/agitated, irritable/over-reactive and impatient.

\section{Scoring system:}

Scores of Depression, Anxiety and Stress are calculated by summing the scores for the relevant items. Within each category, separate symptoms are rated from zero (never) to three (almost always). Zero = never, $1=$ sometimes, $2=$ often, $3=$ almost always.

Table 1. Scoring system

\begin{tabular}{llll}
\hline & Depression & Anxiety & Stress \\
\hline Normal & $0-9$ & $0-7$ & $0-14$ \\
Mild & $10-13$ & $8-9$ & $15-18$ \\
Moderate & $14-20$ & $10-14$ & $19-25$ \\
Severe & $21-27$ & $15-19$ & $26-33$ \\
Extremely Severe & $28+$ & $20+$ & $34+$ \\
\hline
\end{tabular}


Instrument (3): World Health Organization Quality of Life (WHOQOL-BRIEF):

The WHOQOL-BRIEF was developed and validated by Skevington and colleagues 2004. ${ }^{[26]}$ It was adopted and translated into Arabic and tested for content validity and reliability by the researchers. WHOQOL-BRIEF is a selfreport questionnaire that contains 26 items and classifies four domains: seven items for the physical domain, six for psychological, three for social relations, eight items for the environmental domain and items one and two measure the overall quality of life and general health. It is a five-point Likert scale from one to five. The mean score for each domain is calculated and then multiplied by four in order to transform the domain score into a scaled score, with a higher score indicating a higher QOL. When transformed, each domain score is then comparable with the scores used in the original WHOQOL100.

- Domain 1 (Physical health): pain and discomfort, energy and fatigue, sleep and rest, dependence on medication, mobility, activities of daily living, working capacity $(3,4,10,15,16,17,18)$.

- Domain 2 (Psychological health): positive feelings, negative feelings, self-esteem, thinking learning, memory and concentration, body image, spirituality, religion and personal beliefs $(5,6,7,11,19,26)$.

- Domain 3 (Social relations): personal relations, sex, and practical social support (20,21, and 22).

- Domain 4 (Environment): financial resources, information, and skills, recreation and leisure, home environment, access to health and social care, physical safety and security, physical environment, transport (8, $9,12,13,14,23,24,25)$.

Validity: Before starting the data collection, the tool was translated into Arabic and tested for their content validity by a group of five experts in psychiatric and medical-surgical nursing the required modifications were carried out according to their opinion. While instrument two was tested for content validity by Taouk et al. ${ }^{[25]}$

Reliability of the tools: Instrument two tested for reliability by Taouk et al. ${ }^{[25]}$ revealed that the tool is strongly reliable for the DASS $(0.93,0.90$ and 0.93 [alpha] coefficients correspondingly). The instrument three was tested for reliability using test-retest reliability and seemed to be strongly reliable $(r=0.82)$.

\subsection{Procedure}

\subsubsection{Preparatory phase}

Administrative approval: An official approval was obtained by the researchers from the hospital administrator of Menoufia University Hospital.

Pilot study: A Pilot study was conducted on $10 \%$ of the total sample to evaluate the instruments for clarity and feasibility accordingly and to test the applicability of the study instruments and to determine the time needed to fill in the questionnaire. The necessary adjustments were carried out. Data obtained from the pilot study was excluded from the current results.

Ethical considerations: at the initial interview each patient was informed about the purpose and benefits of the study and informed that their participation is voluntary, also confidentiality, privacy, and anonymity of the patients were assured finally, patients' oral formal consent for participations has been obtained at Medical Outpatient Clinics in Menoufia University Hospital.

\subsubsection{Implementation phase}

(1) Fieldwork: Data collection was conducted from September 2015 to January 2016. The data was collected weekly from 9 a.m. to 11 a.m. Subjects were assigned to group A (intervention group) or B (control group) using the table of random numbers. Accordingly, numbers 0-4 and 5-9 were assigned to A and B respectively. At the beginning of the study, subjects were assessed for depression, anxiety, stress, quality of life and blood glucose level then attended five sessions about standard care then the intervention group attended additional five sessions on relaxation therapy. The termination occurred after losing more than two sessions of the last five sessions. Reassessment occurred after two months from the beginning of the study.

(2) Standard care: Standard care was carried out in five 30-minute sessions that focused on general diabetes information (physiology, clinical pictures, possible complications [vascular, dental], nutrition and diet in addition to basic information about treatments for diabetes). The sessions for the control group were carried out to protect the rights of all patients in care.

(3) Relaxation therapy: Relaxation therapy consisted of five 30-minute sessions that focused on: 1) knowledge and practical instruction for using cognitive and behavioral therapies to recognize and reduce physiological stress effects (such as recognition of major stressors in life, signs, and symptoms of stress, guided imagery, thought-stopping, and deep breathing); 2) education on the health consequences of stress; 3) progressive muscles relaxation (PMR training), PMR training consisted of consecutively tensing and relaxing a prescribed set of muscle groups in the body, 
starting with the feet and progressing through the head, with specific attention paid to tense regions of the body. This was combined with other techniques such as deep breathing and mental imagery to improve relaxation of mind and body. Participants were encouraged to practice muscle relaxation twice a day. During the last session, patients were encouraged to continue practicing relaxation skills.

\subsubsection{Evaluation phase}

- The subjects of both groups were assessed by using instrument (2) and instrument (3) three times pre, postintervention and then after two months after finishing the sessions.

- The subjects of both groups were assessed for blood glucose level three times pre, post-intervention and then after two months after finishing the sessions.

\subsection{Data processing and analysis}

Data were analyzed using the IBM Statistical Package of Social Science (SPSS) version 20. Descriptive and analytical procedures were performed. Tests of significance included McNemar's, Chi-squared and Pearson correlation $(r), p<.05$ was considered statistically significant.

\subsection{Limitations of the study}

The sample size was relatively small, and the study was implemented in only one site.

\section{RESUlts}

Table 2 showed the mean age of the participants was $57.9 \pm 9.36$ and the mean duration of diabetes was $8.79 \pm 6.58$ years. Most of the participants lived in rural areas $(85.7 \%)$ and were married $(81.4 \%)$. More than half of the sample was employed $(54.3 \%)$ and had sufficient income (54.3\%), 38.6\% was illiterate, $70 \%$ had a positive family history of diabetes and $40 \%$ had hypertension.

Anxiety levels improved among the intervention group from the pre to post-intervention phase. As illustrated in Table 3 , more than half of the intervention group had an extremely severe level of anxiety (57.1\%) in the pre-intervention phase compared to zero percent in the post-intervention. The decrease in stress resulted in a greater percentage of participants reporting normal stress levels from a low of $5.7 \%$ pre-intervention to $77.1 \%$ post-intervention. All subjects in the intervention group had normal to mild depression in post-intervention compared to $51.4 \%$ in pre-intervention. The differences between the intervention and control groups were statistically significant regarding anxiety, stress, and depression. This means that the relaxation therapy was effective in improving anxiety, stress, and depression among the intervention group.

Published by Sciedu Press
Table 2. Percentage distribution of patients in both groups according to socio-demographic data $(\mathrm{n}=70)$

\begin{tabular}{|c|c|c|}
\hline \multirow{2}{*}{ Socio-demographic characteristics } & \multicolumn{2}{|c|}{ Studied group } \\
\hline & No. & $\%$ \\
\hline Age/years $(\overline{\mathrm{x}} \pm S D)$ & \multicolumn{2}{|c|}{$57.9 \pm 9.36$} \\
\hline Range & \multicolumn{2}{|c|}{$32-75$} \\
\hline \multicolumn{3}{|l|}{ Residence: } \\
\hline - Urban & 10 & 14.3 \\
\hline - Rural & 60 & 85.7 \\
\hline \multicolumn{3}{|l|}{ Level of education: } \\
\hline - Illiterate & 27 & 38.6 \\
\hline - Primary education & 15 & 21.4 \\
\hline - Secondary education & 12 & 17.1 \\
\hline - University & 16 & 22.9 \\
\hline \multicolumn{3}{|l|}{ Marital state: } \\
\hline - Married & 57 & 81.4 \\
\hline - Widowed & 13 & 18.6 \\
\hline \multicolumn{3}{|l|}{ Occupation : } \\
\hline • Employed & 38 & 54.3 \\
\hline - Not employed & 32 & 45.7 \\
\hline \multicolumn{3}{|l|}{ Income /month: } \\
\hline - Enough & 38 & 54.3 \\
\hline - Not enough & 32 & 45.7 \\
\hline \multicolumn{3}{|l|}{ Family history of diabetes: } \\
\hline - Positive & 49 & 70 \\
\hline - Negative & 21 & 30 \\
\hline \multicolumn{3}{|l|}{ Other health problems: } \\
\hline - None & 20 & 28.6 \\
\hline - Hypertension & 28 & 40.0 \\
\hline - Gastritis & 4 & 5.7 \\
\hline - Cataract & 1 & 1.4 \\
\hline - Chest disease & 7 & 10.0 \\
\hline - Others & 10 & 14.3 \\
\hline Duration of diabetes $(\overline{\mathrm{x}} \pm S D)$ & \multicolumn{2}{|c|}{$8.79 \pm 6.58$} \\
\hline Range & \multicolumn{2}{|c|}{$1-30$} \\
\hline
\end{tabular}

Table 4 illustrated no significant difference regarding anxiety, stress, and depression scores before and after the intervention of the control group.

Table 5 showed highly statistically significant difference between the intervention and control groups regarding anxiety, stress, and depression post-intervention. Also revealed that $5.7 \%$ of the study subjects had severe and extremely severe anxiety level, compared to $60 \%$ of the control subjects post-intervention, while $34.3 \%$ of the control subjects had severe and extremely severe stress compared to none of the intervention group post-intervention, and the entire of the intervention group had normal to mild depression compared to $68.5 \%$ of the control group post-intervention.

Table 6 demonstrated a significant difference regarding blood glucose level at pre and post-intervention among the intervention and control groups. These results indicated that the improvement of blood glucose level for both studied subjects post intervention. 
Table 3. Distribution of anxiety, depression and stress of the intervention group subjects pre and post intervention $(\mathrm{n}=35)$

\begin{tabular}{|c|c|c|c|c|c|}
\hline \multirow{3}{*}{ Studied variable } & \multicolumn{4}{|c|}{ Cases } & \multirow{3}{*}{$\begin{array}{l}\text { McNemar } \\
p \text {-value }\end{array}$} \\
\hline & \multicolumn{2}{|c|}{ Pre-intervention } & \multicolumn{2}{|c|}{ Post intervention } & \\
\hline & No. & $\%$ & No. & $\%$ & \\
\hline \multicolumn{6}{|l|}{ Anxiety: } \\
\hline - Normal & 5 & 14.3 & 18 & 51.4 & \multirow{5}{*}{.001} \\
\hline - Mild & 3 & 8.6 & 9 & 25.7 & \\
\hline - Moderate & 5 & 14.3 & 6 & 17.1 & \\
\hline - Severe & 2 & 05.7 & 2 & 5.7 & \\
\hline $\begin{array}{l}\text { - Extremely severe } \\
\text { - Stress }\end{array}$ & 20 & 57.1 & 0 & 0.0 & \\
\hline Normal: & 2 & 5.7 & 27 & 77.1 & \multirow{5}{*}{.001} \\
\hline - Mild & 2 & 5.7 & 5 & 14.3 & \\
\hline - Moderate & 8 & 22.9 & 3 & 8.6 & \\
\hline - Severe & 13 & 37.1 & 0 & 0.0 & \\
\hline - Extremely severe & 10 & 28.6 & 0 & 0.0 & \\
\hline \multicolumn{6}{|l|}{ Depression: } \\
\hline - Normal & 18 & 51.4 & 26 & 74.3 & \multirow{5}{*}{.001} \\
\hline - Mild & 0 & 0.0 & 9 & 25.7 & \\
\hline - Moderate & 5 & 14.3 & 0 & 0.0 & \\
\hline - Severe & 3 & 8.6 & 0 & 0.0 & \\
\hline - Extremely severe & 9 & 25.7 & 0 & 0.0 & \\
\hline Total DASS Score $(\overline{\mathbf{x}} \pm S D)$ & \multicolumn{2}{|c|}{$60.7 \pm 24.5$} & \multicolumn{2}{|c|}{$22.1 \pm 12.0$} & $\begin{array}{l}5.16^{*} \\
.001\end{array}$ \\
\hline
\end{tabular}

Note. ${ }^{*}$ Wilcoxon test

Table 4. Distribution of anxiety, depression and stress of the control group subjects pre and post intervention $(\mathrm{n}=35)$

\begin{tabular}{|c|c|c|c|c|c|}
\hline \multirow{3}{*}{ Studied variable } & \multicolumn{4}{|c|}{ Control } & \multirow{3}{*}{$\begin{array}{l}\text { McNemar } \\
p \text {-value }\end{array}$} \\
\hline & \multicolumn{2}{|c|}{ Pre-intervention } & \multicolumn{2}{|c|}{ Post-intervention } & \\
\hline & No. & $\%$ & No. & $\%$ & \\
\hline \multicolumn{6}{|l|}{ Anxiety: } \\
\hline - Normal & 1 & 2.9 & 1 & 2.9 & \multirow{5}{*}{.433} \\
\hline - Mild & 1 & 2.9 & 4 & 11.4 & \\
\hline - Moderate & 17 & 48.6 & 9 & 25.7 & \\
\hline - Severe & 8 & 22.9 & 14 & 40.0 & \\
\hline - Extremely severe & 8 & 22.9 & 7 & 20.0 & \\
\hline \multicolumn{6}{|l|}{ Stress: } \\
\hline - Normal & 5 & 14.3 & 6 & 17.1 & \multirow{5}{*}{.902} \\
\hline - Mild & 6 & 17.1 & 7 & 20.0 & \\
\hline - Moderate & 10 & 28.6 & 10 & 28.6 & \\
\hline - Severe & 7 & 20.0 & 4 & 11.4 & \\
\hline - Extremely severe & 7 & 20.0 & 8 & 22.9 & \\
\hline \multicolumn{6}{|l|}{ Depression: } \\
\hline - Normal & 16 & 45.7 & 11 & 31.4 & \multirow{5}{*}{.291} \\
\hline - Mild & 5 & 14.3 & 13 & 37.1 & \\
\hline - Moderate & 11 & 31.4 & 8 & 22.9 & \\
\hline - Severe & 1 & 2.9 & 1 & 2.9 & \\
\hline - Extremely severe & 2 & 5.7 & 2 & 5.7 & \\
\hline Total DASS Score $(\overline{\mathbf{X}} \pm S D)$ & $51.2 \pm 18.8$ & & 53.2 & & $\begin{array}{r}1.28^{*} \\
.197\end{array}$ \\
\hline
\end{tabular}

Note. ${ }^{*}$ Wilcoxon test 
Table 5. Comparison between both groups regarding anxiety, depression, and stress level post-intervention $(\mathrm{n}=70)$

\begin{tabular}{|c|c|c|c|c|c|}
\hline \multirow{3}{*}{ Studied variable } & \multicolumn{4}{|c|}{ Post-intervention } & \multirow{3}{*}{$\begin{array}{l}\chi^{2} \\
p \text {-value }\end{array}$} \\
\hline & \multicolumn{2}{|c|}{ Cases } & \multicolumn{2}{|c|}{ Control } & \\
\hline & No. & $\%$ & No. & $\%$ & \\
\hline \multicolumn{6}{|l|}{ Anxiety: } \\
\hline - Normal & 18 & 51.4 & 1 & 2.9 & \multirow{5}{*}{$\begin{array}{c}33.7 \\
.001\end{array}$} \\
\hline - Mild & 9 & 25.7 & 4 & 11.4 & \\
\hline - Moderate & 6 & 17.1 & 9 & 25.7 & \\
\hline - Severe & 2 & 5.7 & 14 & 40.0 & \\
\hline - Extremely severe & 0 & 0.0 & 7 & 20.0 & \\
\hline \multicolumn{6}{|l|}{ Stress: } \\
\hline - Normal & 27 & 77.1 & 6 & 17.1 & \multirow{5}{*}{$\begin{array}{c}29.4 \\
.001\end{array}$} \\
\hline - Mild & 5 & 14.3 & 7 & 20.0 & \\
\hline - Moderate & 3 & 8.6 & 10 & 28.6 & \\
\hline - Severe & 0 & 0.0 & 4 & 11.4 & \\
\hline - Extremely severe & 0 & 0.0 & 8 & 22.9 & \\
\hline \multicolumn{6}{|l|}{ Depression: } \\
\hline - Normal & 26 & 74.3 & 11 & 31.4 & \multirow{5}{*}{$\begin{array}{c}19.3 \\
.002\end{array}$} \\
\hline - Mild & 9 & 25.7 & 13 & 37.1 & \\
\hline - Moderate & 0 & 0.0 & 8 & 22.9 & \\
\hline - Severe & 0 & 0.0 & 1 & 2.9 & \\
\hline - Extremely severe & 0 & 0.0 & 2 & 5.7 & \\
\hline
\end{tabular}

Table 6. Comparison of blood glucose level between pre and post-intervention among both studied subjects $(\mathrm{n}=70)$

\begin{tabular}{|c|c|c|c|}
\hline Blood glucose level & $\begin{array}{l}\text { Cases } \\
\bar{x}_{ \pm S D}\end{array}$ & $\begin{array}{l}\text { Control } \\
\overline{\mathrm{x}}_{ \pm S D}\end{array}$ & $\begin{array}{l}t \text {-test } \\
p \text {-value }\end{array}$ \\
\hline Pre-intervention & $375.3 \pm 94.5$ & $373 \pm 61.9$ & $\begin{array}{c}0.106 \\
.916\end{array}$ \\
\hline Post-intervention & $254.9 \pm 53.8$ & $335.2 \pm 61.7$ & $\begin{array}{c}5.79 \\
.001\end{array}$ \\
\hline $\begin{array}{l}t \text {-test } \\
p \text {-value }\end{array}$ & $\begin{array}{c}10.4 \\
.001\end{array}$ & $\begin{array}{c}5.59 \\
.001\end{array}$ & \\
\hline
\end{tabular}

Figure 1 revealed no significant difference in all domains of quality of life scores except environment domain and overall quality of life scores among intervention and control groups before the intervention.

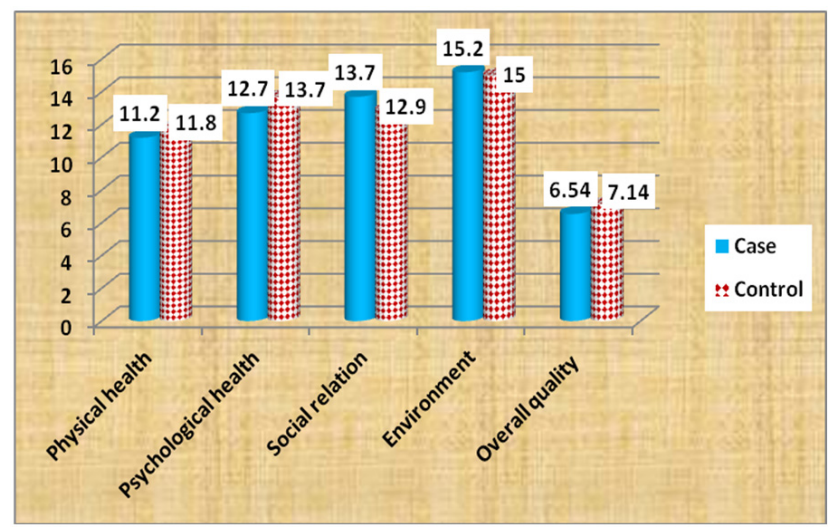

Figure 1. Comparison of quality of life between intervention and control groups before the intervention $(\mathrm{n}=70)$
Figure 2 showed statistically significant difference in the quality of life between intervention and control groups after the intervention. This result means that the quality of life of diabetic patients improved after the relaxation therapy.

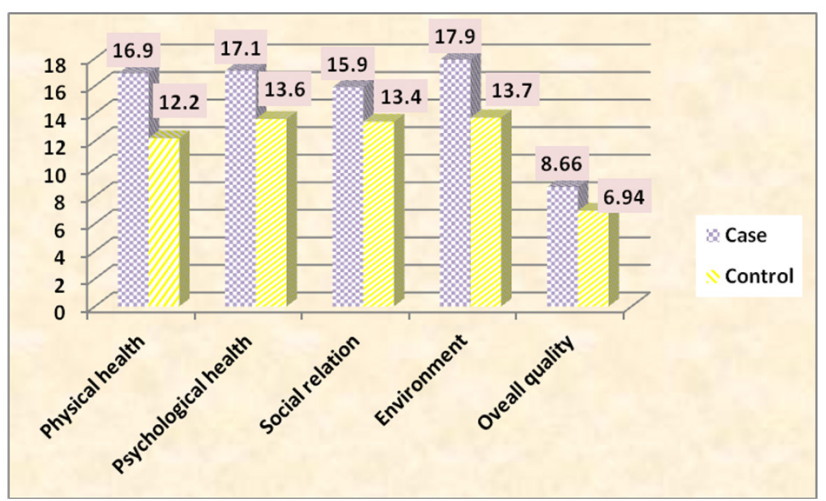

Figure 2. Comparison of quality of life between intervention and control groups after the intervention $(\mathrm{n}=70)$ 


\section{Discussion}

Diabetic patients are challenged by their disease and are at high risk for experiencing psychological difficulties; also self-care behavior, poor glycemic management and diabetic problems linked with depression and decreased the quality of life. ${ }^{[27,28]}$ Diabetes treatment, as insulin, can influence the quality of life positively, by maintaining the blood sugar level at a normal level, or negatively, by causing hypoglycemia. ${ }^{\text {[29] }}$

In this respect, the chief concern of this study was to evaluate the effect of relaxation therapy on depression, anxiety, stress, quality of life, and blood glucose level among patients. diagnosed with T2DM.

\subsection{Regarding depression, anxiety and stress scores (see} Tables 3-5)

This study indicated an improvement of anxiety level, stress, and depression among the intervention group subjects with a statistically significant difference between both groups after the intervention. These may be related to regularly practicing relaxation in a way that increased their bodily awareness thereby enhancing their feelings of calm and in control. This result corresponds with the findings, ${ }^{[30,31]}$ which reported the positive effects of relaxation practice on depression and anxiety.

Furthermore, the results were in accordance with Hassan et al. ${ }^{[32]}$ conclude that significant differences were observed in anxiety level, stress, and depression between two groups of their study after 10 weeks and three months, follow-up. Also, $\mathrm{Xu}^{[33]}$ reported that various relaxation training could mitigate anxiety has been confirmed by various research. Methods of relaxation in these studies include progressive muscle relaxation, music relaxation, biofeedback relaxation training, three-line relaxation and imagination relaxation, and the subjects include students, all sorts of clinical patients, pregnant, maternal women and military personnel. other research study ${ }^{[34]}$ noted that reduction of anxiety was associated with a reduction in psychomotor, agitation, weakness and distrust. Moreover, Yu et al. ${ }^{[35]}$ found that muscle relaxation was effective in the treatment of stress $r=0.40$. Furthermore ${ }^{[36]}$ reported that after the treatment, the anxiety score of study subjects was significantly lower than before. The results were contradicted with Rodi et al. ${ }^{[37]}$ who stated that there were no significant changes in depression when compare results of both groups. This discrepancy may be attributed to the difference in sampling techniques and different measuring tools.

\subsection{Regarding the level of blood glucose (see Table 6)}

Regarding the blood glucose level, Avianti et al. ${ }^{[38]}$ reported that the progressive relaxation was effective in reducing the level of blood glucose in type II diabetics. And Khaviani et al. ${ }^{[39]}$ reported that decreasing blood glucose values after two hours postprandial with practicing relaxation exercise at $p<.001$. While Mashudi ${ }^{[40]}$ showed that a significant effect on the level of blood glucose was found when performing the progressive muscle relaxation for one week with duration of 25-30 minutes for each session (3 times/week). These results were consistent with the current study which showed decreasing in blood glucose level for both studied groups with a significant difference between both groups post-intervention. This may be related to the difference of education program for both studied groups. Also, Soo et al. ${ }^{[41]}$ reported that a literature on psychological interventions in Type II diabetic patients conclude that overall psychological interventions may help in reducing stress, anxiety, and related negative emotions, also help in improving glycemic control.

\subsection{Regarding the quality of life (see Figures 1 and 2)}

Regarding the quality of life, the current work revealed that the quality of life was improved in the test group after intervention with no difference in the control group. This result was in coincide with the primary finding of the study done by Valerie et al. ${ }^{[42]}$ who claimed that exercise training improved physical health and quality of life in Type II diabetics' regardless of the training program (aerobic, resistance, or combined). Also, the current observation was enforced by data from Green et al. ${ }^{[43]}$ who reported improvement in the quality of life after an exercise training intervention. Moreover, Hassan et al. ${ }^{[32]}$ noted that differences had existed in the quality of life scores among the groups of their study after 10 weeks and three months, follow-up. In contrast, the results of the current study were inconsistent with Per et al., ${ }^{[44]}$ mentioned stress relieving techniques had limited, if any, positive effect on quality of life in diabetic patients with type II, they cannot, however, rule out that specific patient groups perceived higher levels of stress could show benefits with this kind of treatment.

\section{Conclusions}

Relaxation therapy improved depression, anxiety, stress, quality of life, and blood glucose levels among patients diagnosed with T2DM.

\section{RECOMMENDATION}

Relaxation therapy, patient education programs and treatment protocols should be integrated into the medical outpatient clinic to assist patients diagnosed with T2DM to cope with their stress, anxiety, depression, and enhance blood glucose control.

\section{CONFLicts OF InTEREST Disclosure}

The authors declare they have no conflict of interest. 


\section{REFERENCES}

[1] Diabetes fact sheet Global report on diabetes. World Health Organization, Geneva. 2016. Available from: http://wwwwho.int/med iacentre/factsheets/fs312/en/

[2] World Health Organization. Prevalence of raised fasting blood glucose. 2008 [cited 2014 August 17]. Available from: http://www . who.int/gho/ncd/risk_factors/blood_glucose/en/

[3] Ghuloum S, Bener A, Burgut T. Ethnic Differences in Satisfaction with Mental Health Services among Psychiatry Patients. Open Psychiatr J. 2010; 4: 19-24. https : //doi .org/10.2174/18743005 01004010019

[4] Bos M, Agyemang C. Prevalence, and complications of diabetes mellitus in Northern Africa, a systematic review. BMC Public Health. 2013; 13: 387. PMid: 23617762. https ://doi .org/10.1186/14 71-2458-13-387

[5] Bener A, Al-Hamaq A, Dafeeah E. High Prevalence of Depression, Anxiety, and Stress Symptoms Among Diabetes Mellitus Patients. The Open Psychiatry Journal. 2011; 5: 5-12. https: //doi.org/10.2174/1874354401105010005

[6] El-Adl T, Talaat A, Elsayed O, et al. Psychiatric Morbidity and Glycemic Control in Type 2 Non-Obese Diabetic Egyptian Patients. Life Science Journal. 2013; 10(1). Available from: http: //www.lifesciencesite.com

[7] Brown G, Brown M, Sharma S, et al. Quality of life associated with diabetes mellitus in an adult population. J Diabetes Complications. 2000; 14: 18-24. https://doi.org/10.1016/S1056-8727(00 ) $00061-1$

[8] Lloyd C, Smith J, Weinger K. Stress and diabetes: a review of the links. Diabetes Spectrum. 2005; 18: 121-127. https://doi.org/ 10.2337/diaspect.18.2.121

[9] Ciechanowski P, Katon W, Russo J, et al. The relationship of depressive symptoms to symptom reporting, self-care and glucose control in diabetes. Gen Hosp Psychiatry. 2003; 25: 246-252. https://doi.org/10.1016/S0163-8343(03)00055-0

[10] Polonsky W. Understanding and assessing diabetes-specific quality of life. Diabetes Spectrum. 2000; 13: 36-41.

[11] Evans A, Pinzur M. Health-related quality of life of patients with diabetes and foot ulcers. Foot Ankle Int. 2005; 26: 32-37. PMid: 15680116 .

[12] Musselman D, Betan E, Larsen H, et al. Relationship of depression to diabetes types II and II: epidemiology, biology, and treatment. Biol Psychiatry. 2003; 54: 317-29. https ://doi .org/10.1016/S000 6-3223 (03) 00569-9

[13] Gonzalez J, Esbitt S, Schneider H, et al. Psychological co-morbidities of physical illness A behavioral medicine perspectives. Ch(2) Psychological Issues in Adults with Type 2 Diabetes. 2011; 73-121.

[14] Lin T, Liu X, Lan Y, et al. Depression Level and Relevant Factors of the Old Patients with Diabetes Mellitus Type 2. Chinese Journal of Gerontology. 2013; 33: 2115-2117.

[15] lbright T, Parchman M, Burge S. Predictors of self-care behavior in adults with type II diabetes: an RRNeST Study. Fam Med. 2001; 33 : 354-60. PMid: 11355645.

[16] American Diabetes Association. Living with diabetes. Last Reviewed: June 7, 2013. Available from: http://www.diabetes.org/living-with-diabetes/co mplications/mental-health/stress.html

[17] Dunning T. Care of People with Diabetes: A Manual Nursing Practice. Melbourne: Blackwell Publishing; 2003. Melbourne. https: //doi.org/10.1002/9780470774649

[18] Potter P, Perry A. Complementary and Alternative therapies: Study Guide for Fundamentals Nursing. Mosby Elsevier. $8^{\text {th }}$ (ed). 2013; 136: 139 .

Published by Sciedu Press
[19] Mcgrady A. The Effects of biofeedback in diabetes and essential hypertension. Cleveland Clinic Journal of Medicine. 2010; 77: 68-71. PMid: 20622080. https://doi.org/10.3949/ccjm.77.s3.12

[20] Shaw J, Sicree R, Zimmet P. Global estimates of the prevalence of diabetes for 2010 and 2030. Diabetes Research and Clinical Practice. 2010; 87(1): 4-14. PMid: 19896746. https ://doi.org/10.101 6/j.diabres.2009.10.007

[21] Fisher L, Skaff M, Mullan J, et al. A longitudinal study of affective and anxiety disorders, depressive affect and diabetes distress in adults with type 2 diabetes. Diabetic Medicine. 2008; 25(9): 10961101. PMid: 19183314. https://doi.org/10.1111/j.1464-5 491. 2008.02533.x

[22] Mitsonis C, Dimopoulous N, Psarra V. Clinical implications of anxiety in diabetes: A critical review of the evidence base. European Psychiatry. 2009; 24(1): 526. https ://doi.org/10.1016/S092 4-9338(09) 70759-X

[23] Tuncay T, Musabak I, Gok D, et al. The relationship between anxiety, coping strategies and characteristics of patients with diabetes. Health and Quality of Life Outcomes. 2008; 6(79). https : //doi.org/10.1186/1477-7525-6-79

[24] Lovibond S, Lovibond P. Manual for the depression, anxiety and stress scales. (2nd Ed) Sydney: Psychology Foundation. 1995.

[25] Taouk M, Lovibond P, Laub R. Psychometric Properties of an Arabic version of the depression, anxiety, and stress scale (DASS). 2001.

[26] Skevington S, Lotfy M, O'Connell K. The World Health Organization's WHOQOL-BREF quality of life assessment: Psychometric properties and results of the international field trial: A Report from the WHOQOL Group. Quality of Life Research. 2004; 13: 299-310. PMid: 15085902. https://doi.org/10.1023/B: QURE.0000018486.91360.00

[27] Katon W, Lin E, Von Korff M, et al. Collaborative care for patients with depression and chronic illnesses. N Engl J Med. 2010; 363: 2611-2620. PMid: 21190455. https://doi.org/10.1056/NEJM oa1003955

[28] Stanton A, Revenson T, Tennen H. Health psychology: psychological adjustment to chronic disease. Annu Rev Psychol. 2007; 58: 565-92. PMid: 16930096. https://doi.org/10.1146/annurev.psych. 58.110405 .085615

[29] De Ridder D, Geenen R, Kuijer R, et al. Psychological adjustment to chronic disease. Lancet. 2008; 19: 246-55. https ://doi .org/10 .1016/S0140-6736(08)61078-8

[30] Hosseinzadeh P, Djazayery A, Mostafavi S, et al. Brewer's Yeast improves blood pressure in type 2 diabetes mellitus. Iranian Journal of Public Health. 2013; 42: 602-609. PMid: 23967428.

[31] Georgiades A, Zucker N, Friedman K, et al. Changes in depressive symptoms and glycemic control in diabetes mellitus. Psychosom Med. 2007; 69: 235-241. PMid: 17420441. https ://doi .org/10 .1097/PSY . Ob013e318042588d

[32] Hassan M, Mehrabi A, Attari A, et al. The effectiveness of cognitive behavioral stress management training on glycemic control, psychological distress and quality of life in people with type II diabetes Iranian Journal of clinical psychology. 2012; 1(1): 57-64.

[33] Xu Y. Influence of relaxation training on curative effect of patients with anxiety. Chinese Journal of Mis-diagnostics. 2011; 11: 20702071

[34] Sharpley C, Bitsika V, Christie D. Causal 'mapping' of depression and anxiety among prostate cancer patients: a preliminary interview study. J Mens Health Gender. 2007; 4: 402-8. https : //doi.org/10.1016/j.jmhg.2007.09.001

[35] Yu D, Lee D, Woo J. Effects of relaxation therapy on psychologic distress and symptom status in older Chinese patients with heart 
failure. J Psychosomatic Res. 2007; 62: 427-37. PMid: 17383494. https://doi.org/10.1016/j.jpsychores.2006.10.012

[36] Zheng Y, Zhou Y, Lai Q. Effect of twenty four move shadow boxing combined with psychosomatic relaxation on depression and anxiety in patients with type 2 diabetes. Psychiatria Danubina. 2015; 27(2): 174-179. PMid: 26057313.

[37] Rodi M, Ming F, Hassan A, et al. Impact of applied progressive deep muscle relaxation training on the level of depression, anxiety and stress among prostate cancer patients: A Quasi-Experimental Study. Asian Pacific J Cancer Prev. 2013; 14(4): 2237-2242. https : //doi.org/10.7314/APJCP. 2013.14.4.2237

[38] Avianti N, Desmaniarti Z, Rumahorbo H. Progressive Muscle Relaxation Effectiveness of the Blood Sugar Patients with Type II Diabetes. Open Journal of Nursing. 2016; 6: 248-254. https: //doi.org/10.4236/ojn.2016.63025

[39] Khaviani M, Bahoosh N, Azima S, et al. The Effect of relaxation on blood sugar and blood pressure changes in women with gestational diabetes: A Randomized Control Trial. Iranian Journal of Diabetes and Obesity. 2014; 6(1): 14-22.
[40] Mashudi P. Progressive Muscle Relaxation Terhadap kadar Glukosa darah pasien diabetes type 2 di Rumah Sakit Umum Daerah Raden Mattaher Jambi. 2011. Available from: http://lontar/ui .ac.id

[41] Soo H, Lam S. Stress management training in diabetes mellitus. Journal of Health Psychology. 2009; 14(7): 933-943. PMid: 19786520. https : //doi.org/10.1177/1359105309341146

[42] Valerie H, Myers A, Mcvay M, et al. Exercise training and quality of life in individuals with type 2 diabetes. Diabetes Care. 2013; 36(7): 1884-1890. PMid: 23404304. https ://doi.org/10.2337/dc12 $-1153$

[43] Green A, Fox K, Grandy S. Impact of regular exercise and attempted weight loss on quality of life among adults with and without type 2 diabetes mellitus. J Obesity. 2011; 1720-73. https: //doi.org/10.1155/2011/172073

[44] Per E, Wändell C, Carlsson G, et al. Measuring possible effect on health-related quality of life by tactile massage or relaxation in patients with type 2 diabetes. 2012; 20(1-2): 8-15. 